\title{
Aplikasi Pendeteksi Plat Nomor Kendaraan Berbasis Raspberry Pi Menggunakan Website Untuk Pelanggaran Lalu Lintas
}

\author{
Siska Aulia ${ }^{1}$, Popy Maria $^{2}$, Ramiati $^{3}$ \\ 1,2,3 Jurusan Teknik Elektro, Politeknik Negeri Padang \\ *Corresponding Author, email:siska.auliaa@gmail.com
}

\begin{abstract}
Abstrak - Kendaraan bermotor di Indonesia terdiri dari kendaraan roda dua dan kendaraan roda empat. Jumlah kendaraan bermotor semakin bertambah tiap tahun. Semakin tinggi volume kendaraan semakin tinggi pula tingkat pelanggaran lalu lintas. Setiap pelanggar akan dikenakan tilang oleh petugas tilang jika pengguna kendaraan tidak mematuhi aturan berkendara. Proses tilang di Indonesia masih secara manual yaitu menggunakan kertas dengan menuliskan pelanggaran yang di lakukan oleh pelanggar pada selembar kertas. Artikel ini merupakan upaya untuk mempermudah masyarakat dan polisi dalam pelanggaran lalu lintas. Artikel ini dirancang aplikasi pendeteksi plat nomor kendraan dan website pelanggaran lalu lintas. Proses identifikasi plat diawali dengan pengambilan citra plat melalui kamera atau webcam berbasis Raspberry Pi. Hasil citra plat menggunakan kamera Raspberry Pi dilakukan pengolahan citra digital plat kendaraan dengan metode segmentasi dan Optical Character Recognition (OCR) menggunakan matlab. Hasil karakter plat kendaraan yang diperoleh digunakan sebagai input untuk mengidentifikasi pelanggaran lalu lintas. Bentuk pelanggran lalu lintas dapat dilihat pada website tilang. Berdasarkan hasil pengujian OCR terbukti mampu mengenali citra plat kendaraan. Kamera berbasis Raspberry Pi untuk komunikasi jarak jauh atau wireless. Hasil dari website pelanggaran tilang digunakan sebagai bukti untuk memproses pengendara yang telah melanggar pada lalu lintas.
\end{abstract}

Kata Kunci: pelanggaran lalu lintas, OCR, matlab, Web, Raspberry Pi

Abstract-Motorized vehicles in Indonesia consist of two-wheeled vehicles and four-wheeled vehicles. The number of motorized vehicles is increasing every year. The higher the vehicle volume the higher the level of traffic violations. Every violator will be charged a ticket by the ticketing officer if the vehicle user does not obey the driving rules. The ticketing process in Indonesia is still manually using paper by writing violations committed by violators on a piece of paper. This article is an attempt to make it easier for the public and police in traffic violations. This article is designed for vehicle license plate detection applications and traffic violation websites. The plate identification process begins with taking a plate image through a Raspberry Pi-based camera or webcam. The plate image results using the Raspberry Pi camera are carried out by processing the vehicle plate digital image by segmentation methods and Optical Character Recognition (OCR) using matlab. The vehicle plate character results obtained are used as input to identify traffic violations. The form of traffic violations can be seen on the traffic ticket website. Based on the results of OCR testing proved to be able to recognize the image of the vehicle plate. Raspberry Pi based camera for long distance or wireless communication. The results from the traffic ticket website are used as evidence to process motorists who have violated traffic.

Keywords: traffic violations, OCR, Web, matlab, Raspberry Pi

(C) 2019 Elektron Jurnal Ilmiah

\section{I.PENDAHULUAN}

Pertambahan jumlah kendaraan bermotor dalam tiap tahun semakin meningkat. Situasi ini mejadikan lalu lintas semakin padat dan tidak terkendali. Pertambahan jumlah kendaraan bermotor akan mempengaruhi tingkat pelanggaran dan kecelakaan berlalu lintas [1]. Menurut (Soesilo, 1988) Tingginya angka pelanggaran lalu lintas merupakan salah satu penyebab tingginya kecelakaan lalu lintas, dengan mengambil tindakan yang tegas terhadap pelanggaran lalu lintas tanpa kecuali akan merubah tingkah laku pengemudi dalam berlalu lintas dan pada gilirannya meningkatkan keselamatan dalam berlalu lintas.
Pencatatan pelanggaran dan kecelakaan yang berlaku saat ini masih menggunakan sistem pencatatan manual yang belum berintegerasi dengan teknologi secara online[1]. Artikel sebelumnya (Gilrandy,2015) Rancang Bangun Sistem Pencatatan Pelanggaran dan Kecelakaan Lalu Lintas Secara Online Berbasis Web dan Mobile Application. Pada artikel ini dikembangkan pencatatan pelanggaran lalu lintas dengan mengcapture plat nomor kendaraan ,kemudian diidentifikasi plat kendaraan berbasis Web.

Plat nomor kendaraan merupakan nomor identitas dari setiap kendaraan yang ada[2]. Identifikasi plat nomor kendaraan dengan memanfaatkan kamera pada perangkat mobile, CCTV atau webcam, dan menggunakan metode 
pengolahan citra digital. Nomor kendaraan diidentifikasi dengan metode Optical Character Recognition (OCR) [3]. Pengolahan citra dalam mendeteksi plat kendaraan sangat diperlukan yaitu mengkonversi citra gambar karakter menjadi teks tulisan.

Pada artikel ini dirancang aplikasi pendeteksi plat nomor kendaraan berbasis Raspberry Pi (RPi) menggunakan website untuk pelanggaran lalu lintas. Plat kendaraan dicapture dengan kamera dan webcame berbasis Raspberry Pi. Hasil identifikasi plat dapat dilihat pada website pelanggran lalu lintas. Artikel ini bertujuan dapat membantu masyarakat dan kepolisian dalam upaya pencatatan pelanggaran dan kecelakaan kendaraan bermotor berdasarakan plat nomor kendaraan. Perancangan website merupakan sarana pemberitahuan pelanggaran lalu lintas untuk masyarakat dan kepolisian.

\section{METODE}

Pada tahap ini dilakukan kegiatan pembahasan literatur dari suatu penulisan yaitu merencanakan sistem identifikasi plat nomor kendaraan dan website pelanggaran lalu lintas. Penulis mengumpulkan data-data serta mempelajari teori dasar yang relevan dari berbagai sumber seperti buku, internet , narasumber dan penelitian yang telah dilakukan yang berkaitan dengan artikel penulis.

Pada tahap ini kegiatan yang dilakukan penulis adalah membuat blok diagram sistem pendeteksi plat nomor kendaraan dan website pelanggran lalu lintas berdasarkan gambar 1 .

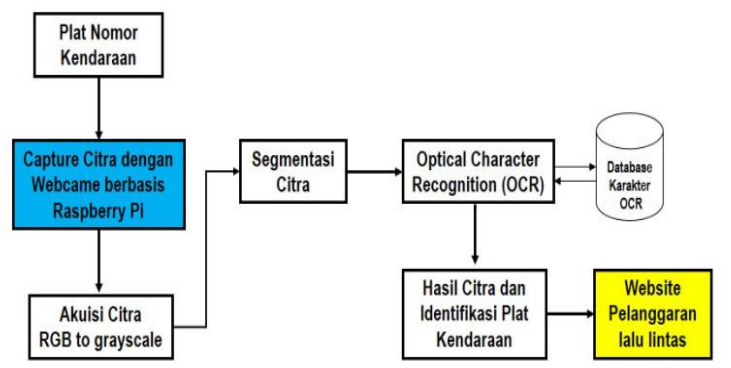

Gambar 1. Blok Diagram Sistem Pendeteksi Plat Nomor Kendaraan dan Website Pelanggaran Lalu lintas

Pada artikel ini sistem yang dibangun terbagi 2 yaitu pertama sistem pengolahan citra plat nomor kendaraan untuk identifikasi plat nomor kendaraan. Kedua website pelanggaran lalu lintas. Pengolahan citra digital plat menggunakan metode segmentasi citra dan OCR.

\section{A. Perancangan Perangkat Keras}

Pada artikel ini pembuatan perangkat keras berbasis Raspberry Pi. Webcam IP dengan menggunakan router, dimana target capaian capture gambar dari plat nomor kendaraaan. Desain rancangan perangkat keras artikel secara umum dapat dilihat pada gambar 2 .

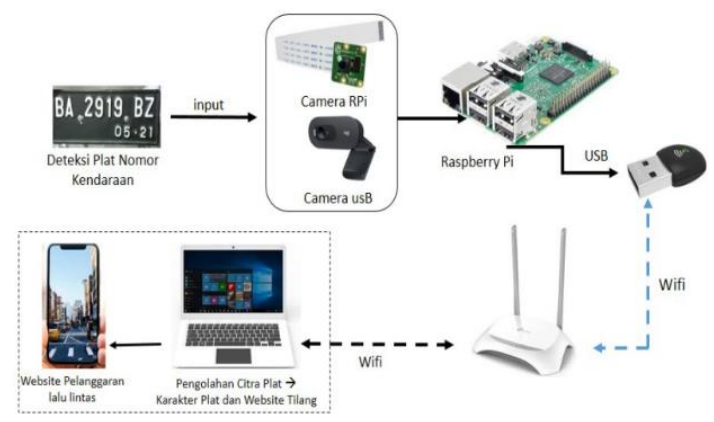

Gambar 2. Desain Rancangan Sistem Identifikasi

Plat Nomor Kendaraan Berbasis Raspberry Pi

Berdasarkan gambar 1 dan 2 perangkat keras yang dipakai dalam sistem ini berupa 1 unit laptop sebagai user dan Raspberry Pi sebagai mini PC (server) dilengkapi webcame Logitech C270, USB Wi-Fi dongle, dan wifi extender serta 1 unit router Sistem Operasi Mikrotik. Perangkat lunak RPi menggunakan system operasi MotionEyeOS dan aplikasi Motion untuk Surveillance Cam Plat kendaraan dicapture oleh kamera USB pada RPi, jadi fungsi IP ada pada RPi, sedangkan komunikasi pada camera melalui USB. Mini PC yang digunakan adalah Raspberry Pi model B rev 1. Komunikasi antara RPi ke unit laptop (user) menggunakan Wireless LAN (WLAN) melewati router, sedangkan untuk menambah kekuatan sinyal wifi dibutuhkan router tambahan

Sistem pada RPi dimana Webcam menangkap gambar / citra plat kendaraan, dimana kendaraan berada dalam posisi diam. Kemudian data disimpan di storage RPi lalu data diambil dan di kirim ke user melalui Wi-Fi dongle yang sudah menghubungkan $\mathrm{RPi}$ dengan perangkat router dan PC-Client oleh user. Pengolahan Citra Plat Kendaraan menggunakan Matlab versi R2014a, sehingga terdeteksi karakter plat.

\section{B. Perancangan Perangkat Lunak}

Pada tahap ini penulis melakukan proses desain dan pembuatan perangkat lunak untuk akuisisi data, pengambilan data image plat nomor kendaraan, dan pengambilan data pengontrolan server RPi menggunakan USB kamera melalui router LAN. 
Pengolahan citra digital plat nomor kendaraan menggunakan metode OCR adalah pertama proses dimulai dengan preprocessing citra teknik enhancement yaitu transformasi citra RGB (warna) ke dalam bentuk grayscale. Proses kedua filtering untuk mengurangi noise, sehingga hasil citra yang diberikan lebih halus. Proses ketiga segmentasi untuk membagi citra kedalam segmen dan menfokuskan pada objek tertentu. Dan proses pengolahan citra terakhir normalisasi. Normalisasi dilakukan sebelum masuk ke proses pengenalan. Proses ini bertujuan untuk menyesuaikan data citra masukan dengan data citra pada basis data. Kemudian proses optical recognition yaitu objek yang berwarna putih pada metode thresholding menjadi identifikasi karakter. Untuk mengenali karakter pada objek harus menginputkan database optical character recognition, hasil akhir adalah berupa teks teridentifikasi dengan karakter opticial character recognition.

Hasil karakter identifikasi plat nomor kendaraan merupakan input untuk data website pelanggaran lalu lintas. Pada client smartphone polisi, polisi mengcapture plat kendaraan dan mengirim ke admin. Kemudian admin mengendalikan sistem pengolahan citra plat dan hasilnya dikenali karakter /teks dari plat kendaraan tersebut. Pada website polisi akan mencari atau input data teks plat kendaraan. Blok diagram website dapat dilihat pada gambar 3 .
Pinsip kerja pada proses Website adalah server dikendalikan oleh admin, admin bertugas sebagai penginput data, dimana basis data dari website berupa data polisi, data kendaraan. Pada data tilang terbagi dua yaitu kendaraan roda dua dan roda empat, dan data proses tilang, kemudian akan di simpan melalui database masing - masing.

Client smartphone dikendalikan oleh polisi, polisi melakukan proses pelanggaran tilang melalui website berbasis mobile berdasarkan kesalahan dari pengendara, dalam penginputan data pelanggaran tilang ada dilakukan beberapa tahap yaitu menginputkan gambar kendaraan dan bukti kesalahan dari pengendaraan dengan menggunakan kamera smartphone, kemudian menginputkan nomor registrasi kendaraan dan nomor registrasi kendaraan dicari berdasarkan data kendaraan yang di input oleh database kendaraan, selanjtunya menginputkan kesalahan pelanggaran tilang merupakan bukti tertulis pada pelanggaran, kemudian menginputkan pasal - pasal pelanggaran, keterangan pasal, dan denda pasal yang sesuai dengan kesalahan dari pengendara, kemudian diinputkan petugas pemeriksa pelanggaran, hasil pelanggaran tilang di inputkan ke database tilang, dan pemilik kendaraan mendapatkan pesan singkat merupakan bukti dari kesalahan pengendara yang menggunakan kendaraan tersebut. Pemilik kendaraan akan melihat hasil pelanggaran tilang berdasarkan pesan singkat yang di terima.

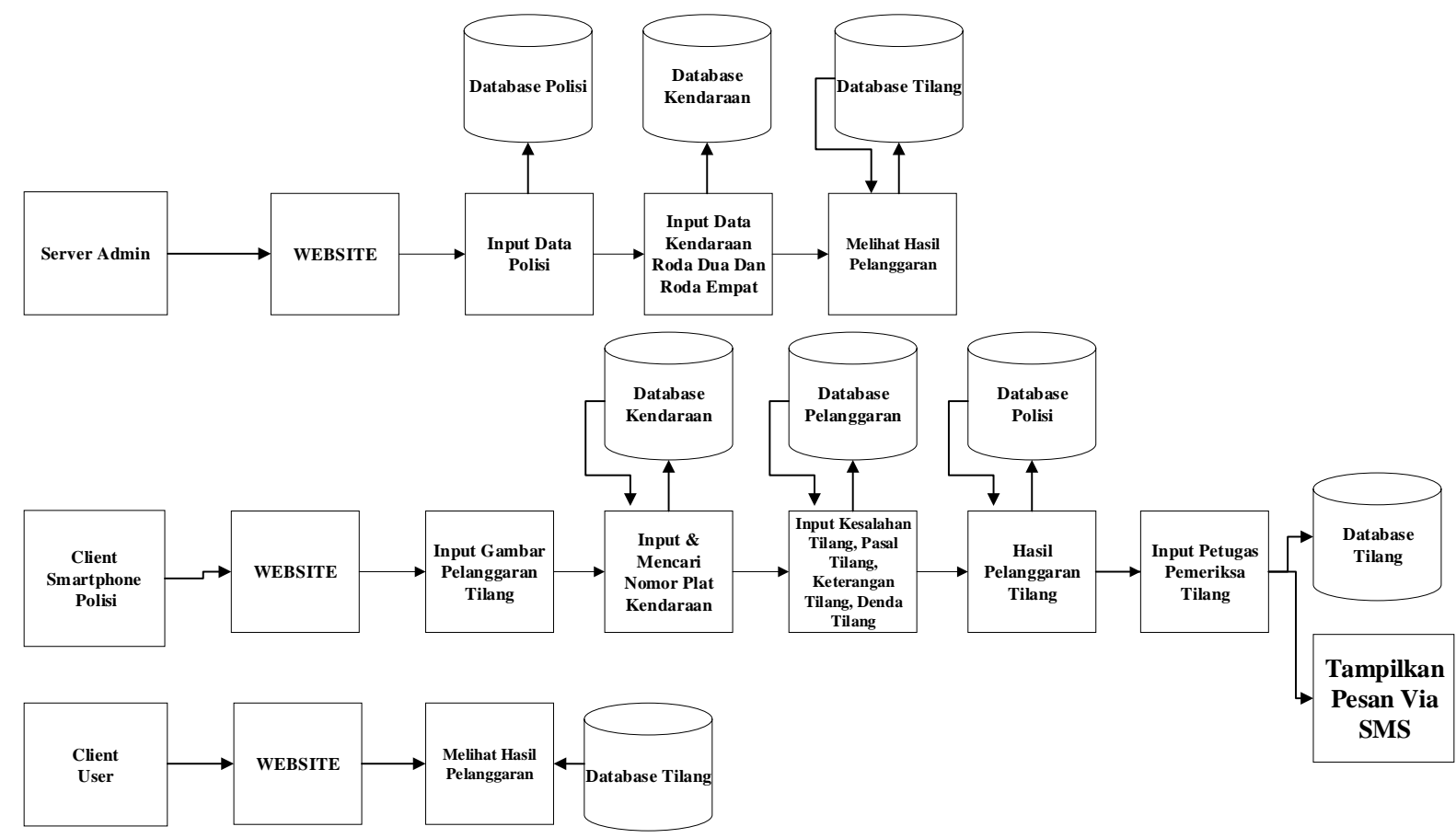

Gambar 3. Blok Diagram Website Pelanggaran Lalu Lintas 


\section{HASIL DAN PEMBAHASAN}

Pengujian dalam artikel ini terbagi dua yaitu pengujian identifikasi karakter plat nomor kendaraan dan aplikasi website pelanggaran lalu lintas. Pengujian identifikasi plat nomor kendaraan menggunakan kamera raspberry Pi dan webcam. Pada gambar 4 pengambilan citra plat nomor mobil, dimana posisi mobil diam melalui program motion kamera raspberry $\mathrm{Pi}$.

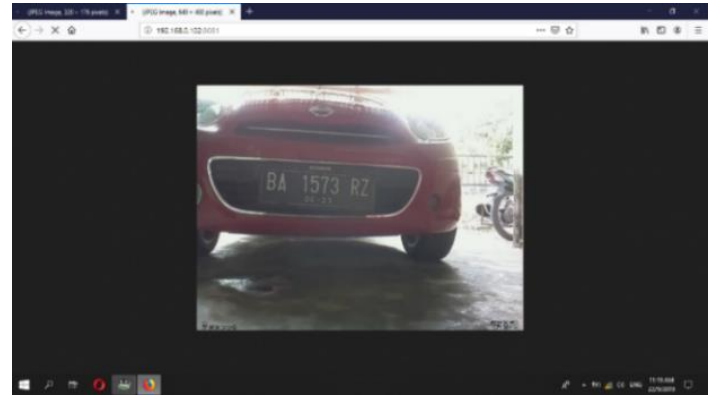

Gambar 4. Hasil Program Motion Kamera Raspberry Pi

Pada artikel ini juga dilakukan pengambilan citra menggunakan webcam berbasis Raspberry Pi. Webcam yang digunakan Logitech C270. Gambar 5 pengambilan citra plat nomor motor melalui program motion webcam berbasis Raspberry Pi.

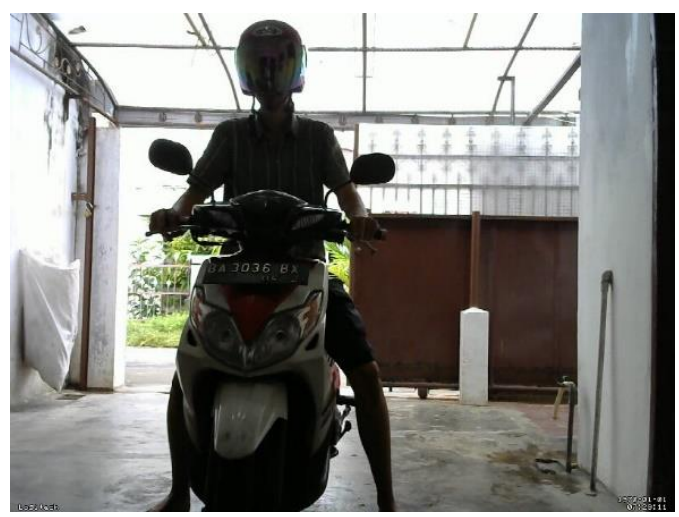

Gambar 5. Hasil Program Motion Webcam Identifikasi Plat Nomor Kendaraan "Motor"

Pengambilan data camera, dibutuhkan software Motion pada Sistem Operasi MotionEyeOs. Konfigurasi pada Motion tersebut dalam capture gambar dilakukan secara manual atau mengambil video dengan time triggering sistem setiap 5 detik. Hasil capture gambar dan data disimpan sementera di memory, lalu data di transfer ke PC user yang telah dikonfigurasi melalui protocol File Transfer Protocol ( FTP ). Untuk melihat stream dari motion, masukan alamat 192.168.0.102:8081 pada browser disisi user. Dimana 192.168.0.102 merupakan IP local address dari router yang digunakan di rumah dan 8081 merupakan port yang digunakan untuk video streaming dengan kamera Raspberry Pi. Hasil stream dari motion seperti pada gambar 4 dan 5 .

Pengolahan sinyal citra plat nomor kendaraan diambil atau diperoleh data dengan mendownload citra dari Raspberry Pi. Pengolahan data citra plat kendaraan dengan metode OCR menggunakan Matlab versi R2014a. Proses dalam sistem, pertama akuisi citra yaitu citra RGB plat dirubah menjadi citra grayscale. Kedua preprocessing citra meliputi proses Imadjust, convert to complement image, convert to biner.. Kemudian proses OCR meliputi segmentasi, normalisasi dan mengkorelasikan citra antara karakter pola plat nomor kendaraan dengan citra template matching. Hasil OCR mengubah citra gambar menjadi tulisan / text, dapat dilihat pada gambar 6. Hasil akhir artikel identifikasi karakter plat kendaraan dan website pelanggaran lalu lintas.

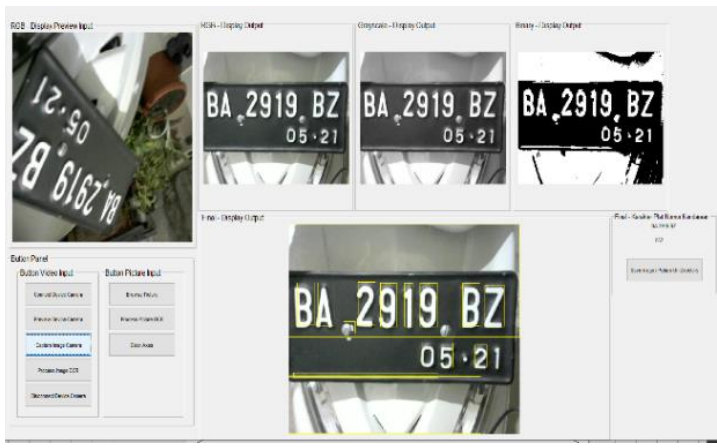

Final - Karakter Plat Nomor Kendaraan BA 2919 BZ

Gambar 6. Hasil Identifikasi Karakter Plat Nomor Kendaraan dengan OCR

Berdasarkan gambar 6, hasil pengujian identifikasi karakter plat kendaraan menggunakan matlab. Hasil persentase keberhasilan identifikasi plat kendaraan berdasarkan gambar 6 adalah $100 \%$. Citra plat nomor pda gambar 6 diatas memiliki pola karakter input "BA 2919 BZ". Artikel dengan menggunakan kamera USB berbasis wireless, data citra diperoleh dari Raspberry Pi dan webcame secara real time melalui program matlab. Hasil karakter plat nomor kendaraan merupakan input untuk website data tilang pada aplikasi pelanggaran lalu lintas.

\section{Pengujian WEBSITE Untuk Pelanggaran Lalu Lintas}

Pada pengujian Website Pelanggaran Tilang, Admin sebagai penginput data kendaraan, data polisi dan data tilang. Polisi sebagai penginput proses data pelanggaran tilang dan user sebagai penglihat data pelanggaran berdasarkan kode transaksi yang telah diproses oleh polisi. Hasil website pelanggaran lalu lintas dapat dilihat pada gambar 7 . 


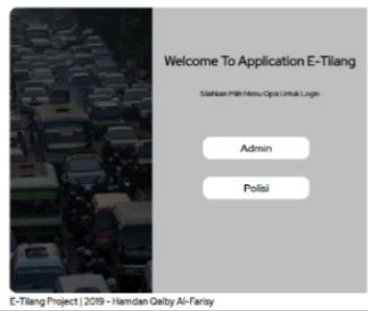

(a)

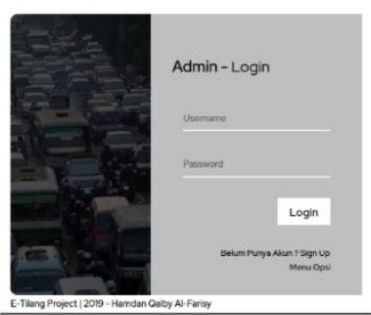

(b) $\ldots \cdot \cdots$

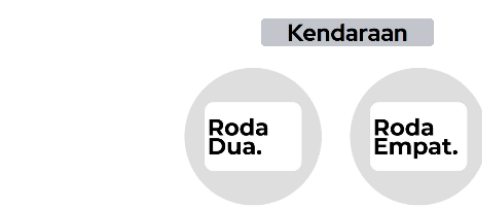

(c)

Gambar 7. Tampilan Aplikasi Website Pelanggaran Lalu lintas (a) Halaman Index, (b) Halaman Admin dan (c) Halaman Kendaraan Pada Admin dan Polisi

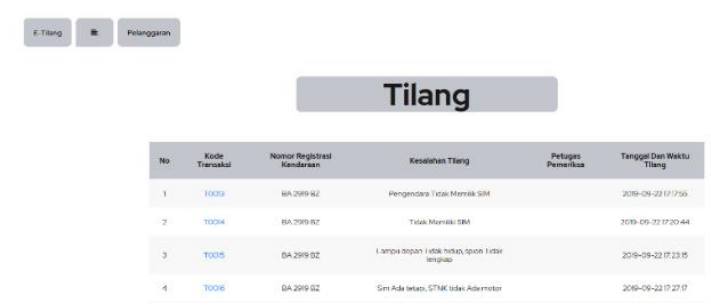

Gambar 8. Halaman Pelanggaran Pada Polisi dan User

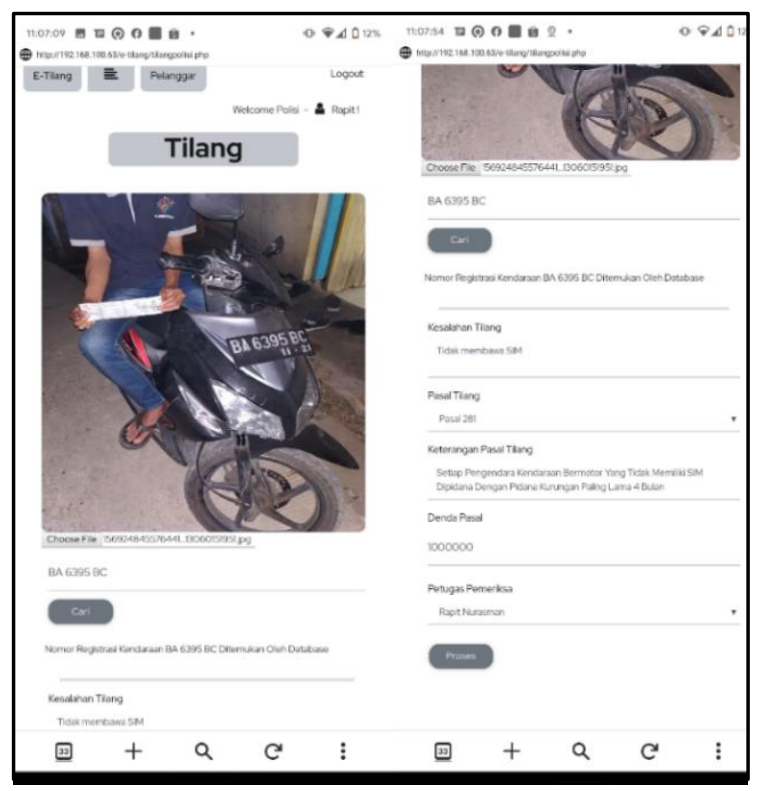

Gambar 9. Pengisian Form Pelanggaran Tilang yang sudah terintergrasi database Kendaraan, database Pasal, dan database Polisi oleh polisi menggunakan smartphone

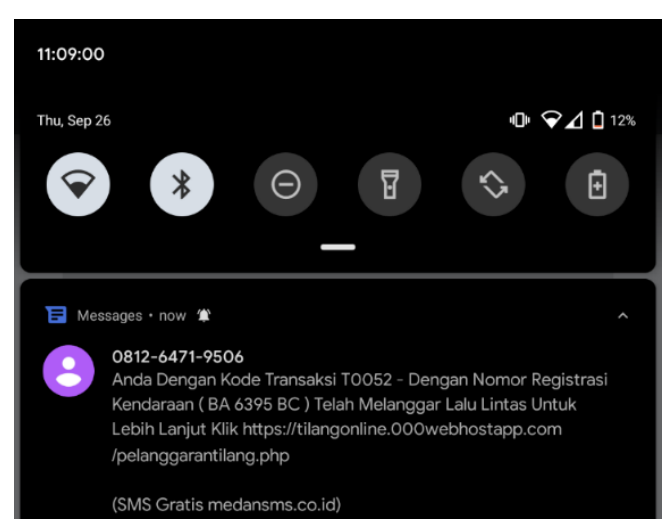

Gambar 10. Hasil Pesan Singkat yang di Kirim Oleh Pemilik Kendaraan Pada Pelanggaran Tilang dengan Nomor Registrasi BA 6395 BC

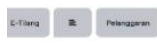

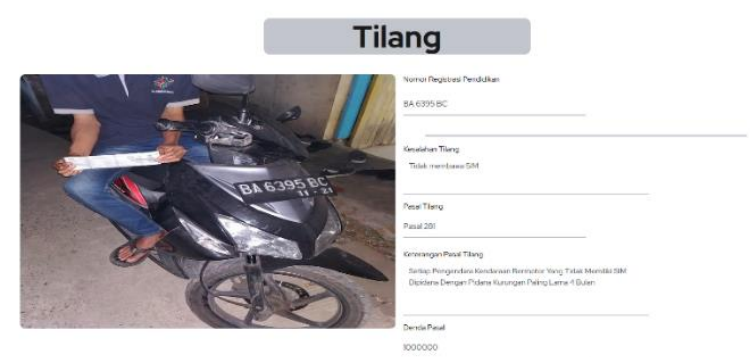

Gambar 11. Melihat Hasil Data Pelanggaran Tilang Pada User Pelanggaran Tilang dengan Nomor Registrasi BA 6395 BC.

Pada hasil pengujian website pelanggaran tilang, server Admin sebagai penginput dan penyunting data polisi, data kendaraan, melihat hasil pelanggaran tilang yang akan di simpan oleh database masing - masing. Polisi sebagai client melakukan proses tilang menggunakan smartphone dalam proses penginputan data pelanggaran tilang dengan mengintergrasikan database kendaraan, database polisi, database pasal. Dan user sebagai client melihat proses pelanggaran tilang dengan smartphone atau desktop laptop.

Pada gambar 7a dan gambar $7 \mathrm{~b}$ merupakan login admin dengan memasukan username dan password yang telah dibuat atau didaftarkan oleh database. Jika username dan password benar maka akan masuk pada gambar 7c yaitu halaman admin, jika username dan password salah dan tidak terbaca oleh database, akan menampilkan pesan kesalahan login pada admin, selanjutnya admin akan menginputkan data polisi dengan mengisikan form pendaftaran data polisi. Tampilan website halaman pelanggaran pada polisi dan user dapat dilihat pada gambar 8 . Bentuk kesalahan tilang disesuaikan dengan kode transaksi dan karakter plat yang telah diidentifikasi.

Pada gambar 9 merupakan pengisian form pelanggaran tilang oleh polisi dengan memasukan gambar pelanggaran pada data pelanggaran , 
memasukan karakter plat yang telah dideteksi melalui pengolahan citra digital OCR. Kemudian mencari plat nomor kendaraan berdasarkan database, memasukan kesalahan tilang, menginputkan pasal - pasal pelanggaran. Pasal pasal pelanggaran sudah terkait dengan keterangan pasal dan dendan pasal, dan memasukan petugas pemeriksa kendaraan. Jika sudah selesai mengisi form proses pelanggaran tilang akan masuk pada database tilang. Kemudian pemilik kendaraan mendapatkan pesan singkat berupa kesalahan atau pelanggaran lalu lintas pada pengendara dapat dilihat pada gambar 10. Hasil akhir merupakan hasil pelanggaran ditampilkan pada halaman website dengan alamat website yang telah diberi pada pesan singkat pada pemilik kendaraan dapat dilihat pada gambar 11.

\section{KESIMPULAN}

Berdasarkan pada hasil perancangan, pengujian dan analisa yang dilakukan kesimpulan artikel yaitu identifikasi plat nomor kendaraan telah berhasil dilakukan menggunakan metode OCR berbasis Raspberry Pi. Website pelanggaran tilang digunakan pada admin dalam penginputan data, penyuntingan data terhadap database polisi dan database kendaraan, polisi dalam penginputan proses tilang pada pelanggaran lalu lintas, dan user dalam penglihatan data kesalahan pelanggaran lalu lintas.

\section{UCAPAN TERIMA KASIH (ACKNOWLEDGEMENT)}

Artikel ini didanai dalam kegiatan penelitian dosen Politeknik Negeri Padang yaitu Penelitian Dana DIPA Politeknik Negeri Padang No. 387/PL9.1.4/PT.01.02/2019.

\section{REFERENSI}

[1] Gilrandy Septiansyah. 2015. "Rancang Bangun Sistem Pencatatan Pelanggaran dan Kecelakaan Lalu Lintas Secara Online Berbasis Web dan Mobile Application" Business Information System, Fakultas Teknik Informatika, Universitas Ciputra Surabaya.

[2] Rusdi Efendi, Endina Putri Purwandari dan FauzanAzhmiSiregar. 2017. Aplikasi Pembacaan Plat Nomor Kendaraan Menggunakan Optical Character Recognition (OCR). Universitas Bengkulu. Seminar Nasional Teknologi Informasi 2017

[3] Achmad Solichin dan Zulfikar Rahman. 2015. Identifikasi Plat Nomor Kendaraan Berbasis Mobile dengan Metode Learning Vector Quantization. Jurnal TICOM Vol.3 No.3 Mei 2015.

[4] Dedy Ashardi. 2013. Rancang Bangun Aplikasi Pemantau Ruangan Melalui Kamera IP Menggunakan Platform Android. Jurnal Sistem dan Teknologi Informasi Vol.1 No.1.

[5] Bambang Yuwono, Simon Pulung Nugroho dan Heriyanto. 2015. Pengembangan Model Public Monitoring System
Menggunakan Raspberry Pi. TELEMATIKA, Vol. 12, No. 02, JULI, 2015, Pp. 123 - 133. ISSN 1829-667X.

[6] Ragil Febrio Giant, Darjat, dan Sudjadi . 2015. Perancangan Aplikasi Pemantau Dan Pengendali Piranti Elektronik Pada Ruangan Berbasis Web. TRANSMISI, 17, (2), 2015, eISSN 2407-6422, 71.

[7] [6] Gede Agus Udayana, I Gede Mahendra Darmawiguna dan I Made Gede Sunarya. 2016. Pengembangan Prototipe Portal Otomatis Dengan Pendeteksian Plat Nomor Kendaraan Berbasis Raspberry Pi. Kumpulan Artikel Mahasiswa Pendidikan Teknik Informatika (KARMAPATI) Volume 5 , Nomor 2, Tahun 2016. ISSN 2252-9063.

[8] Helmi Muhammad Shadiq, Sudjadi, dan Darjat. 2014. Perancangan Kamera Pemantau Nirkabel Menggunakan Raspberry Pi Model B. TRANSIENT, VOL.3, NO. 4, DESEMBER 2014, ISSN: 2302-9927, 547.

[9] Oki fredian Sahrizal. 2013. Aplikasi Pengenalan Plat Nomor Kendaraan dengan Metode Optical Character recognition (OCR). Surakarta: Teknik Elektro Universitas Muhammadiyah Surakarta.

[10] Aditya Riansyah Lesmana. 2012. Identifikasi Plat Nomor Kendaraan Dengan Zone Based Feature Extraction Menggunakan Metode Klasifikasi Backpropagation. Bogor: Institut Pertanian Bogor.

[11] Syahri Muharom. 2019. Pengenalan Nomor Ruangan Menggunakan Kamera Berbasis OCR Dan Template Matching. INFORM : Jurnal Ilmiah Bidang Teknologi Informasi dan Komunikasi . Vol. 4 No. 1, Januari 2019, PISSN : 2502-3470, E-ISSN : 2581-0367 .

[12] Egrit Nurcahyo Wijatsongko, Agfianto Eko Putra dan Bambang Nurcahyo Prastowo. 2015. Sistem Pemantauan Ruangan Dengan Server Raspberry Pi. IJEIS, Vol.5, No.1, April 2015, pp. 65 76. ISSN: 2088-3714.

[13] Fajar Rinto Hadi Putra dan Tri Kuntoro Priyambodo. 2016. Purwarupa Pengendalian Jarak Jauh Pada Mobile Robot Berbasis Web Melalui Jaringan Wireless TCP/IP. IJEIS, Vol.6, No.1, April 2016, pp. 105 116. ISSN: 2088-3714 .

[14] Aprianti Putri Sujana. 2014. Perangkat Pendukung Forensik Lalu Lintas Jaringan. Jurnal Teknik Komputer Unikom Komputika - Volume 3, No.1 - 2014

[15] Kiki Kusumawati dan Dery Willy Cahyadi. 2017. Penerapan Teknologi Optical Character Recognition Untuk Mendeteksi Plat Nomor Kendaraan. Prosiding Seminar Nasional Inovasi Teknologi - SNITek 2017. ISSN 25805495.

[16] Muhamad Irfan Kurniawan, Unang Sunarya dan Rohmat Tulloh. 2018. Internet of Things : Sistem Keamanan Rumah Berbasis Raspberry $\mathrm{Pi}$ dan Telegram Messenger. ELKOMIKA | ISSN (p): 2338-8323. ISSN (e): 2459-9638. Vol. 6 No. 1 Halaman 1 - 15. DOI : http://dx.doi.org/10.26760/elkomika.v6i1.1 Januari 2018. 